\title{
Laboratory generation of new parthenogenetic lineages supports contagious parthenogenesis in Artemia
}

Contagious parthenogenesis - a process involving rare functional males produced by a parthenogenetic lineage which mate with coexisting sexual females resulting in fertile parthenogenetic offspring - is one of the most striking mechanisms responsible for the generation of new parthenogenetic lineages. Populations of the parthenogenetic diploid brine shrimp Artemia produce fully functional males in low proportions. The evolutionary role of these so-called Artemia rare males is, however, unknown. Here we investigate whether new parthenogenetic clones could be obtained in the laboratory by mating these rare males with sexual females. We assessed the survival and sex ratio of the hybrid ovoviviparous offspring from previous crosses between rare males and females from all Asiatic sexual species, carried out cross-mating experiments between F1 hybrid individuals to assess their fertility, and estimated the viability and the reproductive mode of the resulting F2 offspring. Molecular analysis confirmed the parentage of hybrid parthenogenetic F2. Our study documents the first laboratory synthesis of new parthenogenetic lineages in Artemia and supports a model for the contagious spread of parthenogenesis. Our results suggest recessive inheritance but further experiments are required to confirm the likelihood of the contagious parthenogenesis model. 
1 Marta Maccari $^{1,2}$, Francisco Amat ${ }^{1}$, Francisco Hontoria ${ }^{1}$ and Africa Gómez ${ }^{2}$

$2{ }^{1}$ Instituto de Acuicultura de Torre de la Sal (Consejo Superior de Investigaciones Científicas),

312595 Ribera de Cabanes (Castellón), Spain.

$4{ }^{2}$ School of Biological, Biomedical and Environmental Sciences, University of Hull, HU6 7RX, 5 Hull, United Kingdom.

\section{Corresponding author:}

7 Marta Maccari

8 Instituto de Acuicultura de Torre de la Sal (Consejo Superior de Investigaciones Científicas),

912595 Ribera de Cabanes (Castellón), Spain.

10 Phone: +34964319500

11 E-mail: martamaccari@gmail.com 
Introduction

13 Parthenogenesis in animals has evolved through different molecular mechanisms that influence

14 the initial genetic variability of parthenogenetic strains and therefore have important implications

15 on their evolutionary success and persistence (Simon et al., 2003). One of the most striking

16 mechanisms responsible for the generation of new parthenogenetic lineages is contagious

17 parthenogenesis (Simon et al., 2003; Schön et al., 2009). This involves a parthenogenetic lineage

18 able to produce functional males, which mate with coexisting sexual females producing fertile

19 parthenogenetic hybrid offspring. These new parthenogenetic lineages will combine genetic

20 diversity of the maternal sexual species and their paternal parthenogenetic ancestor, including the

21 genetic fragments linked to the parthenogenesis (Simon et al., 2003; Tucker et al., 2013). This

22 mechanism has been documented in aphids and parasitoid wasps (Schneider et al., 2002;

23 Sandrock \& Vorburger, 2011; Delmotte et al., 2013), and most extensively in the Daphnia pulex

24 species complex (Innes \& Hebert, 1988; Paland et al., 2005). In North American D. pulex

25 parthenogenetic lineages, at least two distinct unrecombined haplotypes on chromosome VIII and

26 IX are implied in the sex-limited meiosis suppression (Lynch et al., 2008; Eads et al., 2012;

27 Tucker et al., 2013). These haplotypes leading to obligate parthenogenesis in D. pulex stem from

28 a single recent event of hybridization with its sister taxon D. pulicaria (Xu et al., 2013; Tucker et

29 al., 2013). Multiple new parthenogenetic lineages have arisen since this event as males produced

30 by asexual lineages spread these parthenogenesis-inducing haplotypes by mating with sexual

31 females.

32 Artemia, an anostracan branchiopod commonly known as brine shrimp, is a typical

33 inhabitant of hypersaline inland lakes and costal lagoons and salterns. This genus includes sexual

34 species and lineages of obligate parthenogenetic populations of diverse ploidy levels

35 (Abatzopoulos, 2002), which makes it a good model system to investigate evolutionary

36 transitions between reproductive systems. Parthenogenetic populations are restricted to the Old 
37 World where they co-occur with several sexual species in sympatry in various areas

38 (Abatzopoulos, 2002; Agh et al., 2007; Abatzopoulos et al., 2009; Maccari et al., 2013a). All

39 strains of Artemia can reproduce either ovoviviparously, with the release of free-swimming

40 nauplii broods when they complete their development in the ovisac (therefore, without a dormant

41 phase), or oviparously with the production of broods of diapausing cysts (Browne, 1980;

42 Abatzopoulos, 2002).

43 In Artemia, both sexual and asexual females are heterogametic (ZW) (Stefani, 1963; Bowen,

44 1963; 1965; De Vos 2013). Diploid parthenogenetic lineages reproduce through automictic

45 parthenogenesis, although the cytological details are controversial (Cuellar, 1987). It appears that

46 diploidy restoration results in female offspring genetically identical to the mother barring

47 mutation or recombination (Abreu Grobois, 1987; Stefani 1960). Parthenogenetic diploid

48 Artemia populations produce fully functional males in low proportions (Stefani, 1964; Bowen et

49 al., 1978; MacDonald \& Browne, 1987; Maccari et al., 2013a). Abreu-Grobois and Beardmore

50 (2001) showed that rare males remain heterozygous at the same allozyme loci as their mothers,

51 suggesting that rare males are produced as a result of rare $\mathrm{ZW}$ recombination events. These 'rare

52 males' can generate viable offspring when crossed with females of sexual Asiatic species (Bowen

53 et al., 1978; Cai, 1993; Maccari et al., 2013a), to which they are closely related genetically

54 (Muñoz et al., 2010; Maniatsi et al., 2011; Maccari et al., 2013b), but they are reproductively

55 isolated with other more distantly related species (MacDonald \& Browne 1987). However, the

56 evolutionary role of rare males in the generation of Artemia parthenogenetic lineages is unknown

57 (Maccari et al., 2013a). The occurrence of contagious parthenogenesis has been suggested in light

58 of the polyphyletic nature of maternal diploid parthenogenetic lineages (Maccari et al., 2013b),

59 but we do not know if rare males are able to transmit parthenogenesis to their offspring, a

60 requisite for contagious parthenogenesis. In an early study, Bowen et al. (1978) crossed two

61 parthenogenetic rare males, one from Yamaguchi (Japan) and the other one from Madras (India), 
62 with one sexual female of $A$. urmiana and one $A$. franciscana respectively, and concluded that

63 parthenogenetic reproduction could not be transmitted through males because they failed to 64 obtain parthenogenetic offspring either in hybrid F1, F2 or F2 backcross.

65 Laboratory generation and establishment of unisexual lineages can be a useful tool to 66 complement phylogenetic approaches to identify the mechanism involved in the transition from 67 sexual to parthenogenetic reproduction. However, most laboratory hybrids often exhibit low 68 fertility and survival, or show deformation and abnormalities (Vrijenhoek, 1989; Mantovani et 69 al., 1996). In vertebrates, the first successful laboratory generation of a unisexual hybrid involved 70 the origin of the hybridogenetic fish Poeciliopsis monacha-lucida through crosses of P. monacha 71 females with P. lucida males (Schultz, 1973). Laboratory hybrids of hemiclonal European water 72 frog $R$. esculenta (Rana ridibunda x Rana lessonae) show faster larval growth, earlier 73 metamorphosis, and higher resistance to hypoxic conditions than their parental species and the 74 equivalent hybrids in nature (Hotz et al., 1999). More recently, Lutes et al. (2011) generated self75 sustaining tetraploid lineages of parthenogenetic lizards by pairing males of diploid sexual 76 species Aspidoscelis inornata with females of the triploid parthenogenetic species Aspidocelis exsanguis. In invertebrates, the first laboratory generation of clonal hybrids in D. pulex was 78 obtained by crossing males from obligately parthenogenetic clones with cyclically 79 parthenogenetic females (Innes \& Hebert, 1988). In addition, new lineages of thelytokous 80 parthenogenetic lineages have been obtained in the wasp Lysiphlebus fabarum and in a South 81 African honeybee, Apis mellifera capensis (Lattorff et al., 2005; Sandrock \& Vorburger, 2011).

82 Here we assess the reproductive role of rare males and investigate whether new 83 parthenogenetic clones could be produced in the laboratory as support for the contagious origin 84 of parthenogenetic lineages in Artemia. For this purpose, (1) we assess the survival and sex ratio 85 of the hybrid ovoviviparous offspring obtained from the previous crosses from Maccari et al. 86 (2013a) between rare males and four Asiatic sexual species, (2) we carry out cross-mating 
experiments between these F1 hybrid individuals to assess their fertility, (3) we estimate the viability and the reproductive mode of the resulting F2 offspring; (4) finally we demonstrate genetically that parthenogenetic F2 are indeed the descendants of the original crosses. This study shows that Artemia has the potential of generating parthenogenetic strains through contagious parthenogenesis.

\section{Materials and methods}

\section{Populations and mating experiments}

In a previous study, we set up mating experiments between rare males from the diploid parthenogenetic Artemia population from Bagdad (Iraq, hereafter PD) and sexual females from Central Asian Artemia species to assess the fertility and the reproductive potential of rare males (Maccari et al., 2013a). The females used were from the sexual Asiatic populations, A. urmiana from Koyashskoe Lake (Ukraine, URM), A. sinica from Yuncheng Lake (China, SIN), $A$. tibetiana from Lagkor Co Lake (Tibet, TIB) and Artemia sp. from Kazakhstan (Artemia Reference Center code - ARC1039, unknown locality, KAZ). These interspecific crosses resulted in viable ovoviviparous and oviparous F1 offspring with similar or higher viability than controls (intraspecific sexual crosses)( Maccari et al., 2013a).

\section{Survival rate, sex ratio and reproductive performance of hybrid generations}

For this study, live nauplii obtained from each ovoviviparous F1 hybrid brood were reared separately in jars containing brine at $80 \mathrm{gL}^{-1}$ salinity, kept at $20-24{ }^{\circ} \mathrm{C}$ under mild aeration at a 12D:12L photoperiod and fed a mixture of Dunaliella sp and Tetraselmis sp. (1:1) microalgae every other day. When animals showed signs of reproductive maturity they were counted and sexed to estimate survival rates (the proportion of F2 offpring per pair attaining adulthood) and sex ratio (the proportion of males in the F2 offspring per pair). For this procedure the animals 
110 were placed in Petri dishes with seawater and anaesthetized with a few drops of freshwater

111 saturated with chloroform and examined carefully under a binocular microscope. We tested for

112 deviations from a 50\% sex ratio per cross and per pair using a Chi-square goodness of fit test

113 (Pearson's statistic)(Wilson \& Hardy, 2002). Statistical analyses were performed with SPSS v.

11415.0 (SPSS Inc., Chicago, USA).

115 Reproductive performance of the F1 hybrid individuals was evaluated in F1xF1 cross

116 fertility tests. For this purpose, 24 randomly size-matched hybrid F1 male-female pairs from each

117 cross were transferred into separate small glass beakers $(60 \mathrm{ml})$ under the culture conditions

118 described above. Lifetime quantitative and qualitative reproductive outputs of each pair were 119 monitored every other day during culture medium renewal events. For each paired F1 female we 120 counted the number of unfertilized and fertilized broods, distinguishing the latter in oviparous 121 and ovoviviparous broods. Eggs from unfertilised broods were identified as they are all smaller 122 and white. In ovoviviparous offspring we also recorded the number of live and dead nauplii, and 123 the number of abortive embryos (pale yellow-orange eggs). When oviparous offspring was 124 produced, we counted the number of normally shelled diapausing cysts (pale grainy surface 125 floating in $200 \mathrm{gl}^{-1}$ brine), as opposed to abortive, abnormally shelled embryos (bright brown 126 colour cysts sinking in $200 \mathrm{gl}^{-1}$ brine)( Maccari et al., 2013a).

127 Emerged F2 hybrid nauplii were reared until maturity as described above. They were counted 128 and sexed to estimate their survival rate and sex ratio in the F2 generation. Then, males and 129 females were individually isolated in containers until their deaths to check if females could 130 reproduce in isolation, as would be expected in parthenogenetic individuals. It is possible that 131 some parthenogenetic females could be sterile; in this case, our procedure will underestimate the 132 frequency of parthenogenesis. The proportion of parthenogenetic female offspring produced in 133 each cross was tested against the expectations of $25 \%$ if governed by a recessive allele in a single 134 gene using a Chi-square goodness of fit test. In addition, to test whether the different crosses 
135 produced the same percentage of parthenogenetic female offspring we used a Chi-square

136 homogeneity test.

137 Paternity analysis of parthenogenetic F2 individuals

138 a) Microsatellite analysis

139 The F2 hybrid generation resulting from crosses between rare males and sexual females from $A$.

140 urmiana and Artemia sp. from Kazakhstan included parthenogenetic individuals. In order to rule

141 out contamination and confirm that they were F2 individuals resulting from the original crosses,

142 we screened three microsatellite loci, previously screened in the parental individuals in another 143 study (Maccari et al., 2013a), in the parthenogenetic F2 animals obtained. Each microsatellite 144 locus (Apdq02TAIL, Apdq03TAIL and Apd05TAIL) (Muñoz et al., 2008) was amplified 145 separately in PCRs performed as described in Maccari et al. (2013a). Alleles were scored using 146 the CEQ Fragment Analysis software (Beckman Coulter ${ }^{\mathrm{TM}}$ ) and checked manually. If F2 147 individuals had a paternal allele in any of the loci this would confirm that they were descendants 148 of the diploid parthenogenetic rare males.

149 b) Maternal lineage

150 The F2 resulting from the rare male $\mathrm{x}$ sexual female cross and F1 x F1 cross should carry the 151 maternal DNA of the sexual strain. To establish the maternal lineage of the parthenogenetic F2 152 offspring, a 709-bp fragment of mitochondrial cytochrome $c$ oxidase subunit I (COI) gene region 153 was amplified in the parental (F0) individuals, in the F1 offspring and in the parthenogenetic F2 154 individuals. Total DNA was extracted and PCR was carried out as described previously (Maccari 155 et al., 2013a). PCR amplifications were sent to MACROGEN for sequencing, and the resulting 156 electrophoregrams were checked by eye using CodonCode Aligner v. 3.5 (CodonCode 157 Corporation, Dedham, MA). 


\section{Results}

Survival rate and sex ratio of F1 hybrid offspring

A total of 102 ovoviviparous hybrid F1 broods produced by the crosses between each combination of sexual species with rare males (Maccari et al., 2013a) were reared to maturity. The live nauplii obtained in each brood were morphologically normal. Survival rates to adulthood were over 50\% in all F1 hybrid offspring (Figure 1), and were highest in the F1 PD x SIN (80\%), and lowest in F1 PD x URM and F1 PD x TIB (ca. 56\%)(for the codes of the hybrid crosses see Figure 1). The overall mean sex ratio of F1 offspring across pairs ranged from 49\% males in F1 PD x KAZ cross to $53 \%$ males in F1 PD x TIB cross and did not significantly differ from $50 \%$ in any cross (Figure $1)$.

\section{Reproductive performance of F1 hybrid offspring}

Prior to setting up the crosses, all females were isolated from males for two weeks to ensure that they could not reproduce in isolation (i.e. they were sexual females). No F1 females were able to reproduce when isolated from males. Then, a total of 24 mating pairs (F1 hybrid female x F1 hybrid male) were set up for each F1 produced in each combination of sexual species with rare males. As some individuals died before mating, the final number of experimental pairs ranged from 10 to 22 per cross, which produced a total of 173 fertile and 92 infertile F2 hybrid broods (Table 1). Ovoviviparous and oviparous F2 offspring viability is shown in Figure 2. The percentage of abortive embryos was high in all crosses (between $70 \%$ and $90 \%$ ), while the proportion of live nauplii in all hybrid ovoviviparous broods was low (from $5 \%$ to $25 \%$ ). In oviparous broods, the proportion of properly shelled cysts ranged from $25 \%$ in F2 PD x TIB to $61 \%$ in F2 PD x URM. 
A total of 103 F2 ovoviviparous broods were recorded (Table 1), of which 35 broods from 27 pairs, characterized by the greatest number of nauplii, were followed to assess the survival rate and the sex ratio of the F2 offspring. F2 nauplii were morphologically normal but they had low survival rates when compared to F1 nauplii (Figure 3). No F2 hybrid offspring produced by the crosses between rare male and $A$. tibetiana survived to maturity. The F2 PD x KAZ had the highest survival rate, about 37\%, followed by the F2 PD x SIN (34\%) and F2 PD x URM (24\%).

The overall mean sex ratio across pairs was significantly female-biased in F2 PD x KAZ and F2 PD x URM crosses ( $12 \%$ and $22 \%$ of males respectively; $\chi^{2}=111.25$ and $\left.\chi^{2}=16.49,1 \mathrm{df}, \mathrm{p}<0.05\right)$, but was non-significantly different from $50 \%$ in the F2 PD x SIN (43\% of males; $\chi^{2}=0,1 \mathrm{df}$, $\mathrm{p}<0.05)($ Figure 3). Furthermore, we observed differences in the sex ratio of the F2 offspring among different pairs from the same cross, in particular for F2 PD x KAZ and F2 PD x URM offspring with an even sex ratio (pair 3) while the remaining five pairs had were female biased offspring (see Table 2).

\section{Generation of hybrid parthenogenetic individuals}

Some females isolated from males of all F2 hybrid offspring analysed (when males were present) reproduced parthenogenetically in two of the three crosses. Specifically, 12 out of 41 isolated females (29.27\%) were parthenogenetic in F2 PD x KAZ (four out of the five offspring analysed, Table 2), and two out of $36(5.56 \%)$ isolated females in F2 PD x URM (two of five offspring analysed, Table 2). The percentages of parthenogenetic female offspring in the F2 crosses were 201 significantly different from each other $\left(\chi^{2}=7.24,1 \mathrm{df}, \mathrm{p}<0.05\right)$, and only that one in F2 PD x KAZ 202 did not differ significantly from the expectations of $25 \%\left(\chi^{2}=0.4,1 \mathrm{df}, \mathrm{p}>0.05\right)$ under expectations 
203 of a recessive allele in a single locus determining parthenogenesis. In all but one case,

204 parthenogenetic females were produced in offspring with significantly female-biased sex ratios

205 (Table 2). None of the 21 F2 PD x SIN offspring included females that could reproduce

206 parthenogenetically .

207 Paternity analysis

208 In order to examine the parentage of newly generated hybrid parthenogenetic individuals we 209 integrated the information from the mitochondrial COI and from microsatellites markers, (Table 210 3). Six of the 10 analysed females from pair 4 of the cross F2 PD x KAZ were parthenogenetic 211 and produced F3 clones. As expected, all of them shared their mtDNA haplotype with their sexual 212 grandmother, and amplified one paternal allele in the two informative microsatellite loci, 213 confirming that they were the offspring of the rare male used in the crosses. The F3 generation 214 was overall composed by females and by two rare males with the same genotype as their F2 215 mothers.

216 The F2 offspring of two pairs from the crosses PD x URM (pairs 4 and 7), composed of three 217 and 13 females respectively, included a parthenogenetic female that produced F3 parthenogenetic 218 clones. In both cases, the F2 parthenogenetic female shared its COI haplotype with its sexual 219 grandmother. In one cross, one paternal allele was detected in the F2 hybrid female at each of the 220 three microsatellite loci; in the other cross, the parthenogenetic female inherited one paternal allele 221 at the two informative loci. Most individuals of the F3 generation, composed of females and one 222 rare male in both crosses, have the same genotype as their F2 mothers, with a few exceptions that 223 lacked one of the maternal alleles, suggesting some level of recombination consistent with 224 automixis parthenogenesis. 


\section{5}

226 This study reports for the first time the laboratory generation of parthenogenetic Artemia lineages

227 through hybridization via rare males, i.e. through contagious parthenogenesis (Simon et al., 228 2003), shedding light on the possible evolutionary role of parthenogenetically produced males 229 and the genetic basis of parthenogenesis in this genus.

230 Contagious parthenogenesis may have important evolutionary consequences as it results in 231 the repeated generation of new asexual genotypes, increasing the genetic diversity in 232 parthenogens. This may counteract the loss of asexual genotypes resulting from the accumulation 233 of deleterious mutations (Muller's ratchet) or gene conversion (Tucker et al., 2013) and could 234 contribute to the evolutionary success of parthenogenesis (Simon et al., 2003).

The occurrence of contagious parthenogenesis relies on regular or occasional hybridization with absence of complete reproductive isolation between parthenogenetically produced males and closely related sexual females (Simon et al., 2003). In a previous study, we showed the absence of prezygotic isolation between rare males and Asiatic sexual Artemia species since these males often coexist in the same environment of a sexual species (Abatzopoulos et al. 2006; Agh et al.2007; 2009; Shadrin et al. 2012; Van Stappen, 2007; 2008; Zheng \& Sun, 2013), show normal pairing behaviour and are fully functional and capable of fertilizing eggs from females of sexual Asiatic Artemia species producing viable hybrid offspring (Maccari et al., 2013a). Under laboratory conditions, each combination of sexual species with rare males produced morphologically normal, viable sexual hybrid F1. Their survival rate to adulthood was over $50 \%$ for all the hybrid populations, a high value if when compared to survival of F1 of intraspecific crosses of the different Artemia species (Browne \& Wanigasekera, 2000).

We found that females constitute approximately the $50 \%$ of each F1 hybrid population, an even sex ratio that usually characterizes Artemia sexual populations, and this was confirmed by 
249 their inability to reproduce without males. These results ruled out a dominant gene as the genetic

250 basis of parthenogenesis. Although all laboratory F1 lines were found to combine ovoviviparous

251 and oviparous reproduction, we observed a strong reduction in the reproductive output in all

252 crosses when compared with the reproductive performance of the parental crosses (Maccari et al.,

253 2013a). Ovoviviparous broods were mostly made up by abortive embryos (more than 80\%) in all

254 the crosses and live nauplii represented only $25 \%$ of the offspring in the cross F2 PD x SIN, and

255 less than 10\% in all the other crosses (F2 PD x KAZ, F2 PD x URM and F2 PD x TIB).

256 Oviparity, the production of dormant encysted embryos that are resistant to extreme

257 environmental conditions, was represented by a variable quantity of properly shelled embryos,

258 only $25 \%$ in the F2 PD x TIB increasing up to $61 \%$ in F2 PD x URM. Similarly, a decline in

259 nauplii F2 production occurs in the interspecific crosses between A. tibetiana and A. sinica (Van

260 Stappen, 2003).

261 In contrast to the high survival rates of F1 hybrids, hybrid breakdown was evident in the F2

262 generation. Nauplii from the F2 generations had low survival rates and were completely inviable

263 in the F2 PD x TIB generation. The lower fertility level of F1 laboratory populations and the

264 reduced viability of F2 hybrid individuals suggest partial genetic incompatibility between

265 parthenogenetic males and sexual females. However, the production of some viable offspring

266 both in F1 and F2 in all hybrid crosses is not so surprising given the recent evolutionary origin of

267 diploid parthenogenetic lineages (Holocene) (Muñoz et al., 2010; Maccari et al., 2013b).

268 In two of the three F2 generations (F2 PD x KAZ and F2 PD x URM) we identified 14

269 hybrid females that upon reaching maturity were capable of parthenogenetic reproduction.

270 Surprisingly, these parthenogenetic females were produced by pairs yielding strongly female

271 biased F2 offspring. Genetic analysis confirmed the parentage of the parthenogenetic lineages

272 found as the F2 individuals inherited the COI haplotype from the sexual grandmother but

273 included some paternal alleles at nuclear markers, showing that they were the offspring of the 
274 rare male used in the crosses. Our results contrast with previous observations suggesting that rare

275 males in the genus Artemia are not capable to transmit parthenogenesis-inducing alleles (Bowen 276 et al., 1978).

277 The production of parthenogenetic individuals only in the second generation, suggests that 278 the parthenogenesis-inducing alleles are recessive in Artemia. A single-locus recessive 279 inheritance of obligate parthenogenesis also occurs in Apis mellifera capensis and in Lysiphlebus 280 fabarum (Sandrock et al., 2011; Lattorff et al., 2005; Lattorff et al., 2007). This is in contrast with 281 D. pulex, where the sex-limited meiosis suppression genes are dominant and the asexual clones 282 arise in the first generation (Innes \& Hebert, 1988). If a single recessive locus was responsible for 283 parthenogenesis and there was no differential viability in Artemia, a 25\% of parthenogenetic 284 females would be expected in the F2 generation. The proportion of isolated females that 285 reproduced parthenogenetically differed between the crosses. In the cross F2 PD x KAZ, the 286 overall proportion of parthenogenetic F2 females was $29.27 \%$, not significantly different from $28725 \%$, whereas in the cross F2 PD x URM this was much lower (5.56\%) and significantly different 288 from the expectations for a single recessive locus. These results suggest either differences in the 289 mechanism underlying parthenogenesis between populations, or increased incompatibilities 290 between PD and URM resulting in viability differences linked to the putative locus associated to 291 parthenogenesis. The latter is supported by the lower viability of F2 PD x URM nauplii. The 292 finding of parthenogenetic females only in sex-biased broods suggests that the inheritance of 293 parthenogenesis has a more complex genetic basis, however. Given that females are 294 heterogametic (WZ) (Bowen 1963; 1965; Stefani 1963) and that F1 females are sexual, we can 295 rule out complete sex-linkage (Z-linkage) of the parthenogenesis determining gene, otherwise 296 parthenogenesis should be apparent in the F1, given that all F1 females are WZ with their Z 297 chromosome presumably inherited from their asexual father. Sex-biased sex ratios are not 298 uncommon in hybrid offspring and can be due to the evolution of sex-ratio distorters and counter 
299

300

301

302

303

304

305

306

307

308

309

310

311

312

313

314

315

316

317

318

319

320

321 322 indicate that the incidence of contagious parthenogenesis, if this is the mechanism of origin, must

323 be extremely low in natural environments. Indeed, the rare males must be present in the

evolution of suppressor genes in different lineages (Hurst and Pomiankowski, 1991). Our data, suggests an interaction between a sex ratio distorter (possibly sex-linked) and a parthenogenetically determining factor. Alternatively, the same gene determining parthenogenesis could act as a sex ratio distorter in heterozygous F1 females, increasing the likelihood of transmission of the $\mathrm{W}$ chromosome. Our results do not support differential male mortality, as there was no correlation between brood survival and sex ratio (data not shown). These interpretations must be taken with caution given the limitations of our experimental design and data, as we analysed F2 broods where there was a larger number of nauplii, the survival of the F2 was low, and we cannot rule out some effect of differential sterility. These factors might have biased our conclusions regarding the genetic basis of parthenogenesis. Therefore, to fully understand the genetic basis of parthenogenesis in Artemia additional crosses and a large set of marker loci will be necessary,

The ability of sexual females of A. urmiana and Artemia sp. from Kazakhstan to generate parthenogenetic clones when crossed with rare males is not surprising, as the two main mitochondrial haplogroups of diploid parthenogenetic Artemia lineages are related to these species (Muñoz et al., 2010; Maniatsi et al., 2011; Maccari et al., 2013b). However, the more distantly related $A$. sinica (Baxevanis et al., 2006; Hou et al., 2006) did not produce any parthenogenetic offspring, despite high survival rate in the F2, suggesting that the specific genomic background affect the expression of the gene inducing parthenogenesis. Although repeated gene flow between sexual females and asexual males through contagious parthenogenesis would be expected to result in a regular emergence of asexual strains with diverse maternal origins, the fact that just two, possibly three, maternal origins of parthenogenetic lineages have been identified (Muñoz et al., 2010; Maniatsi et al., 2011; Maccari et al., 2013b) 
324 population at the same time as the sexual females of the related species, and given that both

325 parthenogenetic and sexual species often have different ecological requirements, they may 326 overlap just during part of each season (Amat et al.,1991; Ghomari et al, 2005). In addition, the

327 percentage of rare male production by diploid parthenogenetic females is very low, about 1-16 in 3281000 (Maccari et al., 2013a). Then, as the parthenogenesis occurs in the second generation (i.e. is 329 based on a recessive trait), a F1xF1 mating must occur for parthenogenesis to appear in the 330 offspring. Finally, F2 survival is very reduced, overall making the origin of a parthenogenetic 331 lineage an unlikely event in the wild.

332 Our study is the first to generate new parthenogenetic lineages in Artemia by mating rare 333 males from parthenogenetic genotypes with sexual females, providing evidence that contagious 334 parthenogenesis can potentially occur in the genus Artemia. This conclusion does not rule out that 335 other mechanisms (spontaneous origin or hybridisation) might have been also responsible for the 336 origin of parthenogenetic lineages. Demonstration of contagious parthenogenesis as the 337 mechanism underlying parthenogenesis in Artemia in the wild will necessitate the use of genomic 338 tools. Further studies on hybrid fitness would be necessary to estimate the strength of 339 reproductive isolation and to compare the reproductive performance of laboratory-produced 340 parthenogenetic clones with the parental parthenogenetic strains. The origin of independently 341 reproducing parthenogenetic clones in the laboratory raises the question of the survival of these 342 clones when competing with sympatric sexual species.

343 Given that many parthenogenetic organisms produce males occasionally (van der Kooi \& 344 Schwander 2014) and such males are still able to maintain their functionality, the occurrence of 345 contagious parthenogenesis could be more widespread than currently acknowledged. 


\section{Acknowledgements}

We wish to thank Paul Nichols for his help with microsatellite screening and Mónica Barbosa,

Eva Becerro and Diana Guinot for their help with the laboratory experiments. We thank Maria

José Carmona for her constructive suggestions on a previous version of this manuscript. We thank the editor Tanja Schwander, and David Innes and two anonymous reviewers for their constructive comments that improved substantially the manuscript.

\section{References}

Abatzopoulos, T. J. 2002. Artemia: basic and applied biology. Dordretch, The Netherlands: Kluwer Academic Publishers.

Abatzopoulos T.J, Agh N, Vanstappen G, Razavi-Rouhani S.M, Sorgeloos P. 2006. Artemia sites in Iran. Journal of Marine Biology Ass. U.K. 86: 299-307.

Abatzopoulos, T. J., Amat, F., Baxevanis, A. D., Belmonte, G., Hontoria, F., Maniatsi, S., Moscatello, S., Mura, G., \& Shadrin, N. V. 2009. Updating Geographic Distribution of Artemia urmiana Günther, 1890 (Branchiopoda: Anostraca) in Europe: An Integrated and Interdisciplinary Approach. International Review of Hydrobiology 94: 560-579.

Abreu-Grobois, F. A., \& Beardmore, J. A. 2001. The generation of males by diploid parthenogenetic Artemia cannot occur in the way Stefani suggested. In Proceedings of the 4th International Large Branchiopod Symposium. La Paz, Baja California, Mexico (p. 1).

Abreu-Grobois, F. A. 1987. A review of the genetics of Artemia. In P. Sorgeloos, D. A. Bengtson, W. Decleir, \& E. Jaspers (Eds.), Artemia Research and its Applications, vol. 1: Morphology, Genetics, Strain Characterization, Toxicology. Wetteren, Belgium: Universa Press.

Agh N, Bossier P, Abatzopoulos T.J, Beardmore J.A, Vanstappen G, Mohammadyari A, Ramihian H, Sorgeloos P. 2009. Morphometric and preliminary genetic characteristics of Artemia populations from Iran. International Review of Hydrobiology 94 (2): 194-207.

Agh N., Abatzopoulos, T. J., Kappas, I., van Stappen, G., Razavi Rouhani, S. M., \& Sorgeloos, P. 2007. Coexistence of Sexual and Parthenogenetic Artemia Populations in Lake Urmia and Neighbouring Lagoons. International Review of Hydrobiology 92: 48-60.

Amat, F., Hontoria F., Navarro J.C., Gozalbo A., Varo I.. Bioecología de Artemia (Crustacea, Branchiopoda) en la laguna de La Mata. Colección Técnica Publ. Inst. Cultura "Juan Gil Albert". Diput. de Alicante. 176 pp. 1991.

Baxevanis, A.D., Kappas, I., Abatzopoulos, T.J., 2006. Molecular phylogenetics and asexuality in the brine shrimp Artemia. Molecular Phylogenetics and Evolution 40, 724 - 738. doi:10.1016/j.ympev.2006.04.010.

Bowen, S. T., Durkin, J. P., Sterling, G., \& Clark, L. S. 1978. Artemia hemoglobins: genetic variation in parthenogenetic and zygogenetic populations. The Biological Bulletin 155: 273287.

Bowen, S. T. 1965. The genetics of Artemia salina. V. Crossing over between the $\mathrm{x}$ and $\mathrm{y}$ chromosomes. Genetics 52: 695-710. 
384

385

386

387

388

389

390

391

392

393

394

395

396

397

398

399

400

401

402

403

404

405

406

407

408

409

410

411

412

413

414

415

416

417

418

419

420

421

422

423

424

425

426

427

428

429

430

431

432

Bowen, S. T. The genetics of Artemia salina. II. White, a sex-linked mutation. Biological Bullettin 124: 17-23.

Browne, R. A. 1980. Competition experiments between parthenogenetic and sexual strains of the brine shrimp, Artemia salina. Ecology 61: 471-474.

Browne, R. A., \& Wanigasekera, G. 2000. Combined effects of salinity and temperature on survival and reproduction of five species of Artemia. Journal of experimental marine biology and ecology 244: 29-44.

Cai, Y. 1993. "OPI" Artemia and its crossing experiments. Journal of Ocean University of Qingdao 23: 52-58.

Cuellar O. 1987. The Evolution of Parthenogenesis: A Historical Perspective. In Meiosis. Edited by Peter Moens. Elsevier, Orlando, Florida. Pp 43-104.

Delmotte, F., Sabater-muñoz, B., Prunier-leterme, N., Sunnucks, P., Rispe, C., Simon, J., \& Url, S. 2013. Phylogenetic Evidence for Hybrid Origins of Asexual Lineages in an Aphid Species. Evolution, 57: 1291-1303.

De Vos S, Bossier P, Van Stappen G, Vercauteren I, Sorgeloos P, et al. 2013 A first AFLP-Based Genetic Linkage Map for Brine Shrimp Artemia franciscana and Its Application in Mapping the Sex Locus. PLoS ONE 8(3): e57585. doi:10.1371/journal.pone.0057585.

Eads, B. D., Tsuchiya, D., Andrews, J., Lynch, M., \& Zolan, M. E. 2012. The spread of a transposon insertion in Rec8 is associated with obligate asexuality in Daphnia. Proceedings of the National Academy of Sciences of the United States of America: 1-6.

Ghomari M., Selselet G., Hontoria F., Amat F. 2011. Artemia biodiversity in Algerian Sebkhas Crustaceana 84 (9): 1025-1039.

Hotz, H., Semlitsch, R. D., Gutmann, E., Guex, G. D., \& Beerli, P. 1999. Spontaneous heterosis in larval life-history traits of hemiclonal frog hybrids. Proceedings of the National Academy of Sciences of the United States of America 96: 2171-6.

Hou, L., Bi, X., Zou, X., He, C., Yang, L., Qu, R., Liu, Z., 2006. Molecular systematics of bisexual Artemia populations. Aquaculture Research 37, 671-680. doi:10.1111/j.13652109.2006.01480.x.

Hurst, L. D., \& Pomiankowski, A. (1991). Causes of sex ratio bias may account for unisexual sterility in hybrids: a new explanation of Haldane's rule and related phenomena. Genetics, 128: 841-858.

Innes, D. J., \& Hebert, P. D. N. 1988. The Origin and Genetic Basis of Obligate Parthenogenesis in Daphnia pulex. Evolution 42: 1024-1035.

Lattorff, H. M. G., Moritz, R. F. a, Crewe, R. M., \& Solignac, M. 2007. Control of reproductive dominance by the thelytoky gene in honeybees. Biology letters 3: 292-5.

Lattorff, H. M. G., Moritz, R. F. a, \& Fuchs, S. 2005. A single locus determines thelytokous parthenogenesis of laying honeybee workers (Apis mellifera capensis). Heredity 94: 533-7.

Lutes, A. a., Baumann, D. P., Neaves, W. B., \& Baumann, P. 2011. Laboratory synthesis of an independently reproducing vertebrate species. Proceedings of the National Academy of Sciences, 108: 9910-9915.

Lynch, M., Seyfert, A., Eads, B. D., \& Williams, E. 2008. Localization of the genetic determinants of meiosis suppression in Daphnia pulex. Genetics 180: 317-327.

Maccari, M., Amat, F., \& Gómez, A. 2013. Origin and Genetic Diversity of Diploid Parthenogenetic Artemia in Eurasia. PloS One 8: e83348.

Maccari, M., Gómez, A., Hontoria, F., \& Amat, F. 2013. Functional rare males in diploid parthenogenetic Artemia. Journal of Evolutionary Biology 26: 1934-1948.

MacDonald, G. H., \& Browne, R. A. 1987. Inheritance and reproductive role of rare males in a parthenogenetic population of the brine shrimp, Artemia parthenogenetica. Genetica 75: 4753. 
Maniatsi, S., Baxevanis, A. D., Kappas, I., Deligiannidis, P., Triantafyllidis, A., Papakostas, S., Bougiouklis, D., \& Abatzopoulos, T. J. 2011. Is polyploidy a persevering accident or an adaptive evolutionary pattern? The case of the brine shrimp Artemia. Molecular phylogenetics and evolution 58: 353-64.

Mantovani, B., Tinti, F., Barilani, M., \& Scali, V. 1996. Current reproductive isolation between ancestors of natural hybrids in Bacillus stick insects (Insecta: Phasmatodea ). 77: 261-268.

Muñoz, J., Gómez, A., Green, A. J., Figuerola, J., Amat, F., \& Rico, C. 2010. Evolutionary origin and phylogeography of the diploid obligate parthenogen Artemia parthenogenetica (Branchiopoda: Anostraca). PloS one 5: e11932.

Muñoz, J., Green, A. J., Figuerola, J., Amat, F., \& Rico, C. 2008. Characterization of polymorphic microsatellite markers in the brine shrimp Artemia (Branchiopoda, Anostraca). Molecular Ecology Resources 9: 547-550.

Paland, S., Colbourne, J. K., \& Lynch, M. 2005. Evolutionary history of contagious asexuality in Daphnia pulex. Evolution 59: 800-13.

Sandrock, C., \& Vorburger, C. 2011. Single-locus recessive inheritance of asexual reproduction in a parasitoid wasp. Current Biology 21: 433-7.

Schneider, M. V., Beukeboom, L. W., Driessen, G., Lapchin, L., Bernstein, C., \& Van Alphen, J. J. M. 2002. Geographical distribution and genetic relatedness of sympatrical thelytokous and arrhenotokous populations of the parasitoid Venturia canescens (Hymenoptera). Journal of Evolutionary Biology 15: 191-200.

Schultz, R. 1973. Unisexual Fish: Laboratory Synthesis of a" Species.” Science 179:180-181.

Schön, I., Martens, K., \& van Dijk, P. 2009. Lost Sex: The evolutionary biology of parthenogenesis (I. Schön, K. Martens, \& P. van Dijk, Eds.). Dordrecht: Springer.

Shadrin N.V, Anufriieva E, Galagovets E. 2012. Distribution and historical biogeography of Artemia Leach,1819 (Crustacea, Anostraca) in Ukraine. International Journal of Artemia Biology. 2 (2): 30-42.

Simon, J.-C., Delmotte, F., Rispe, C., \& Crease, T. 2003. Phylogenetic relationships between parthenogens and their sexual relatives: the possible routes to parthenogenesis in animals. Biological Journal of the Linnean Society 79: 151-163.

Stefani, R. 1964. The origin of males in parthenogenetic populations of Artemia salina. Rivista di biologia 57: 147.

Stefani, R., 1963. La digametia femminile in Artemia salina Leach e la constituzione del corredo cromosomico nei biotipi diploide anfigonico e diploide partenogenetico. Caryologia, 16: 629-636.

Stefani, R., 1960. L'Artemia salina pathenogenetica a Cagliari. Rivista di Biologia 53, 463-490.

Tucker, A. E., Ackerman, M. S., Eads, B. D., Xu, S., \& Lynch, M. 2013b. Population-genomic insights into the evolutionary origin and fate of obligately asexual Daphnia pulex. Proceedings of the National Academy of Sciences of the United States of America 110: 15740-5.

van der Kooi, C.J. \& Schwander T., 2014. On the fate of sexual traits under asexuality. Biological Reviews, pp. 000-000. 1 doi: 10.1111/brv.12078.

Van Stappen, G., Sui, L., Xin, N., \& Sorgeloos, P. (2003). Characterisation of high-altitude Artemia populations from the Qinghai-Tibet Plateau, PR China. Hydrobiologia 500: 179192.

Van Stappen G, Yu H, Wang X, Hoffman S, Cooreman K, Bossier P, Sorgeloos P. 2007. Occurrence of allochthonous Artemia species in the Bohai Bay área P.R.China, as confirmed by RFLP analysis and laboratory culture tests. Archiv für Hydrobiologie 170 (1): 21-28. 
481 Van Stappen G. 2008. Artemia biodiversity in Central and Eastern Asia. Ph.D. thesis. Ghent University, Belgium. 224 pp.

Vrijenhoek, R. 1989. Genetic and ecological constraints on the origins and establishment of unisexual vertebrates. In R. M. Dawley \& J. P. Bogart (Eds.), Evolution and ecology of unisexual vertebrates. Albany, New York: New York State Museum (pp. 24-31).

Wilson, K., \& Hardy, I. C. W. 2002. Statistical analysis of sex ratios. In Hardy, Ian, ed. Sex ratios: concepts and research methods. Cambridge University Press, 2002.

Xu, S., Innes, D. J., Lynch, M., \& Cristescu, M. E. 2013. The role of hybridization in the origin and spread of asexuality in Daphnia. Molecular ecology 22: 4549-4561.

Zheng B \& Sun S.C. 2013. Review of the biogeography of Artemia Leach,1819 (Crustacea, Anostraca) in China. International Journal of Artemia Biology. 3 (1):20-50. 


\section{Figure 1}

Survival rate and sex ratio (overall percentage of males) in the $\mathrm{F} 1$ hybrid offspring from Artemia rare males and Asian sexual females.

F1 hybrids are from parental crosses between Artemia urmiana (URM), A. sinica (SIN), $A$. tibetiana (TIB), Artemia sp. from Kazakhstan (KAZ) and diploid parthenogenetic Artemia rare males (PD). Error bars are standard deviations.

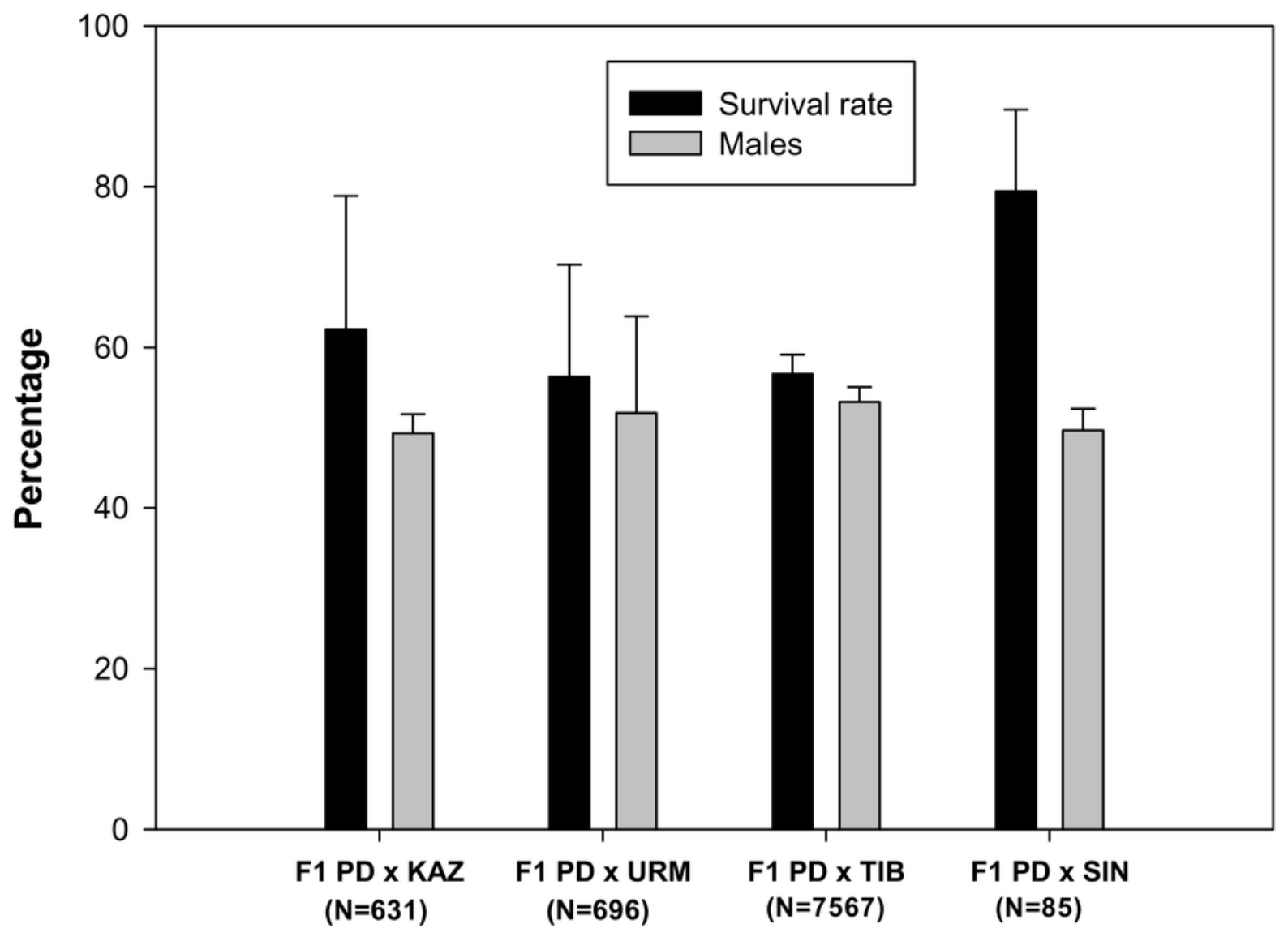




\section{Figure 2}

Reproductive traits (offspring quantity and quality) in F1 hybrids between Artemia rare males and Asian sexual females.

The viability of ovoviviparous and oviparous broods is shown. Error bars are standard deviations.

F2 Offspring viability

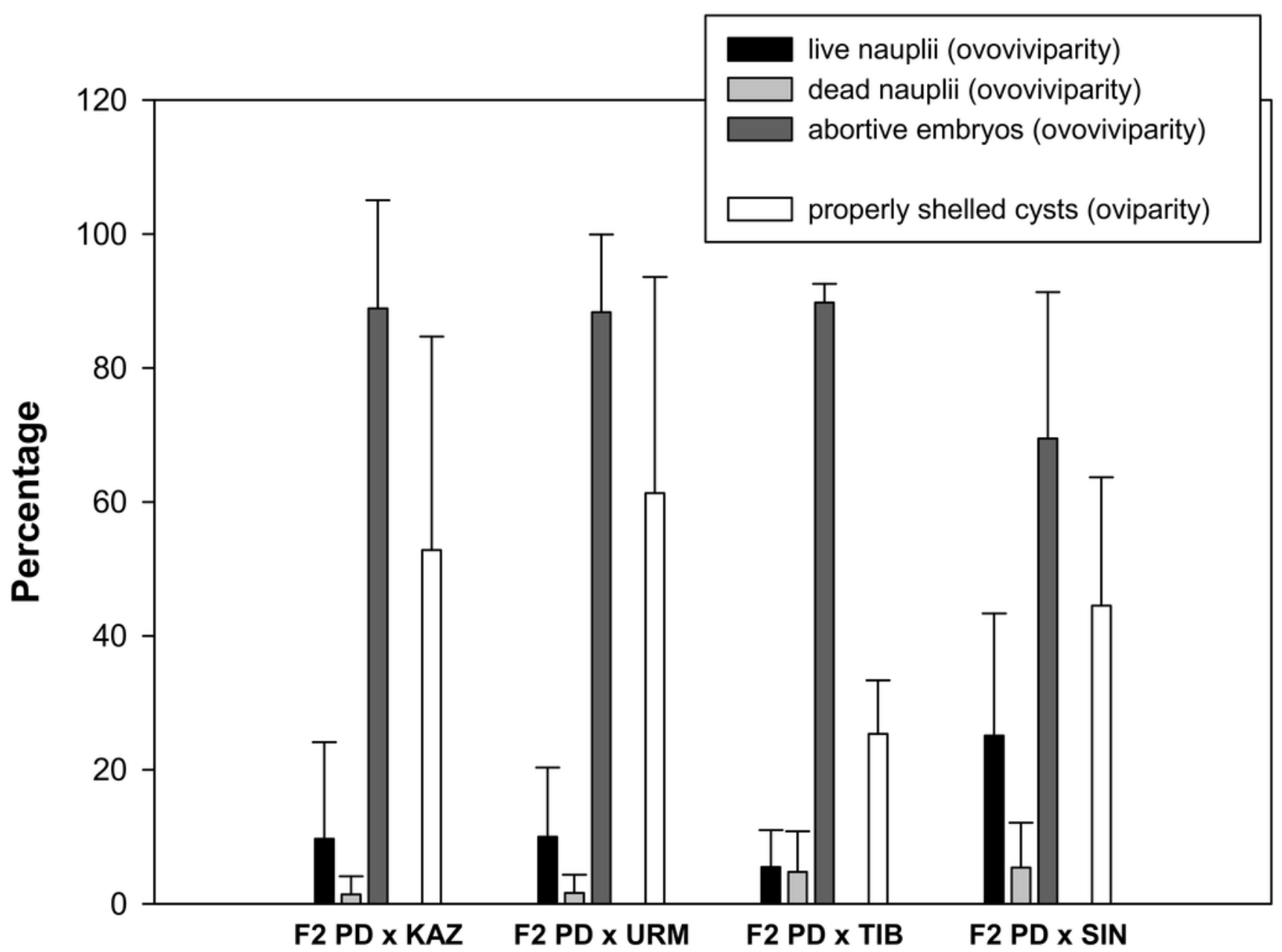




\section{Figure 3}

Survival rate and sex ratio (overall percentage of males) in the F2 hybrid offspring from Artemia rare males and Asian sexual females.

F2 hybrids are from crosses between F1 hybrid individuals which are obtained in the crosses between Artemia urmiana (URM), A. sinica (SIN), A. tibetiana (TIB), Artemia sp. from Kazakhstan (KAZ) and diploid parthenogenetic Artemia rare males (PD). Error bars are standard deviations. Asterisks $(P \leq 0.05)$ indicate significant differences from $50 \%$ sex ratio (Chi-square goodness of fit test was employed).

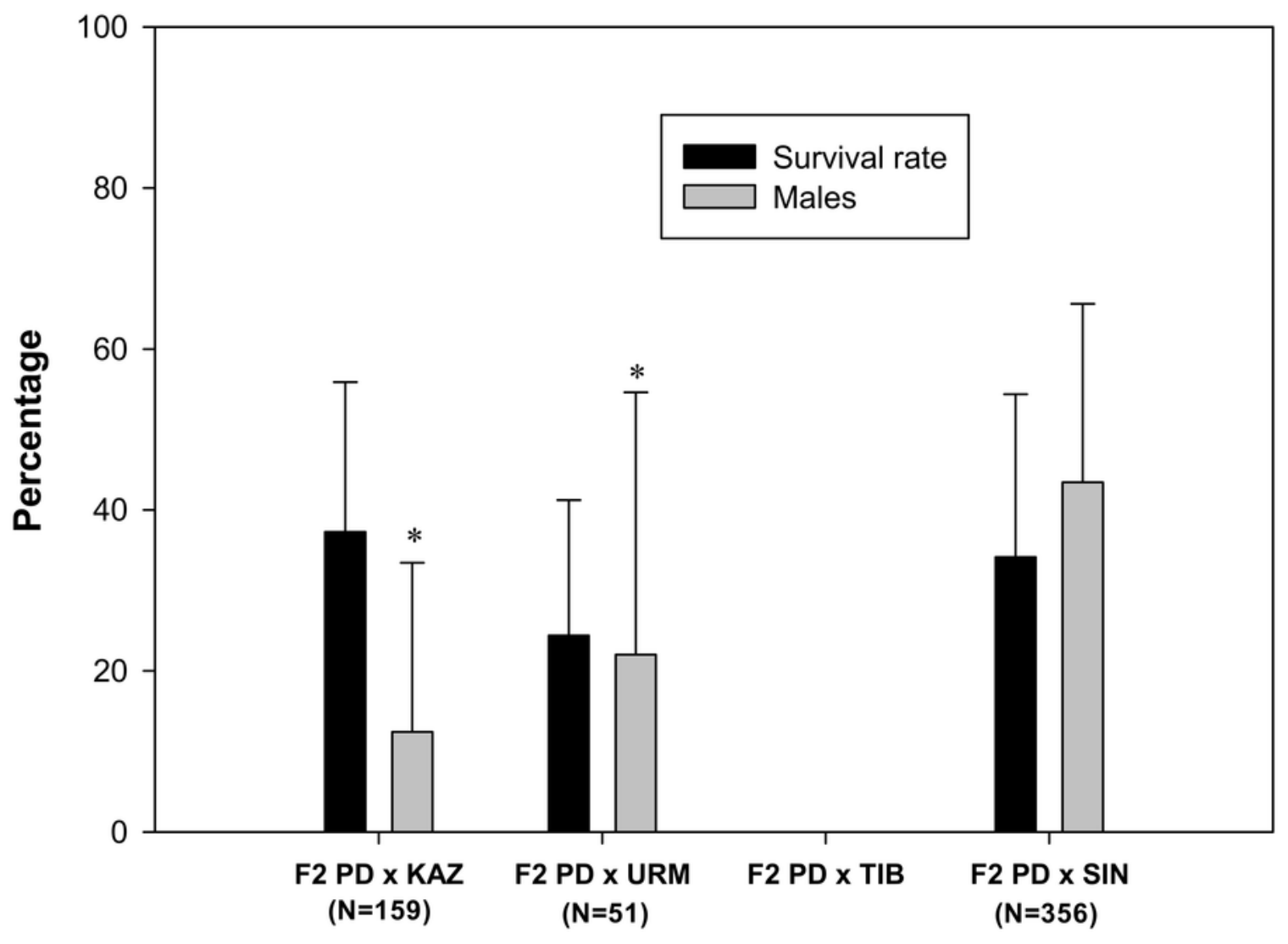




\section{Table 1 (on next page)}

Number of total, fertilized, ovoviviparous and oviparous broods in F1 Artemia hybrid offspring.

F1 hybrids are from parental crosses between Artemia urmiana (URM), Artemia sinica (SIN), Artemia tibetiana (TIB), Artemia sp. from Kazakhstan (KAZ) and diploid parthenogenetic Artemia rare males (PD). 


\begin{tabular}{lccccc}
\hline \multicolumn{1}{c}{ Cross } & Pairs & $\begin{array}{c}\text { Total } \\
\text { broods }\end{array}$ & $\begin{array}{c}\text { Fertilized } \\
\text { broods }\end{array}$ & $\begin{array}{c}\text { Ovoviviparous } \\
\text { broods }\end{array}$ & Oviparous broods \\
\hline F1 PD x KAZ & 18 & 80 & 42 & 37 & 5 \\
F1 PD x URM & 16 & 48 & 26 & 22 & 4 \\
F1 PD x TIB & 10 & 33 & 18 & 4 & 14 \\
F1 PD x SIN & 22 & 104 & 87 & 40 & 47 \\
\hline
\end{tabular}




\section{Table 2 (on next page)}

Sex ratio and parthenogenetic females found in F2 PD x KAZ, F2 PD x URM and F2 PD $x$ SIN Artemia offspring.

Asterisks ( $P \leq 0.05)$ indicate significant differences from $50 \%$ sex ratio (number of males/total individuals) (Chi-square goodness of fit test was employed). All females obtained were isolated until their deaths to determine their mode of reproduction. 


\begin{tabular}{|c|c|c|c|c|c|c|c|}
\hline & $\begin{array}{c}\text { Pai } \\
\mathbf{r}\end{array}$ & $\begin{array}{c}\text { Female } \\
s\end{array}$ & $\begin{array}{c}\text { Male } \\
\mathrm{s}\end{array}$ & Total & $\begin{array}{c}\text { Sex ratio } \\
(\%)\end{array}$ & $\begin{array}{c}\text { Parthenogenetic } \\
\text { females / analysed } \\
\text { females }\end{array}$ & $\begin{array}{c}\text { Parthenogenetic } \\
\text { females } \\
(\%)\end{array}$ \\
\hline \multirow{6}{*}{ F2 PD x KAZ } & 1 & 10 & 0 & 10 & $0.00^{* *}$ & $3 / 10$ & 30 \\
\hline & 2 & 10 & 2 & 12 & $16.67 *$ & $1 / 10$ & 10 \\
\hline & 3 & 7 & 8 & 15 & 53.33 & $0 / 7$ & 0 \\
\hline & 4 & 20 & 0 & 20 & $0.00^{* *}$ & $6 / 10$ & 60 \\
\hline & 5 & 68 & 2 & 70 & $2.86 * *$ & $2 / 4$ & 50 \\
\hline & 6 & 31 & 1 & 32 & $3.13 * *$ & - & - \\
\hline Total & & 146 & 13 & 159 & & $12 / 41$ & 29.27 \\
\hline \multirow{7}{*}{ F2 PD x URM } & 1 & 16 & 3 & 19 & $15.79^{* *}$ & $0 / 16$ & 0 \\
\hline & 2 & 2 & 4 & 6 & 66.67 & $0 / 2$ & 0 \\
\hline & 3 & 2 & 0 & 2 & 0.00 & $0 / 2$ & 0 \\
\hline & 4 & 3 & 1 & 4 & 25.00 & $1 / 3$ & 33.33 \\
\hline & 5 & 2 & 1 & 3 & 33.33 & - & - \\
\hline & 6 & 2 & 0 & 2 & 0.00 & - & - \\
\hline & 7 & 13 & 2 & 15 & $13.37 * *$ & $1 / 13$ & 7.69 \\
\hline Total & & 40 & 11 & 51 & & $2 / 36$ & 5.56 \\
\hline \multirow[t]{14}{*}{ F2 PD x SIN } & 1 & 15 & 13 & 28 & 46.43 & $0 / 15$ & 0 \\
\hline & 2 & 13 & 24 & 37 & 64.86 & $0 / 13$ & 0 \\
\hline & 3 & 6 & 3 & 9 & 33.33 & $0 / 6$ & 0 \\
\hline & 4 & 1 & 3 & 4 & 75.00 & $0 / 1$ & 0 \\
\hline & 5 & 14 & 12 & 26 & 46.15 & $0 / 14$ & 0 \\
\hline & 6 & 10 & 10 & 20 & 50.00 & $0 / 10$ & 0 \\
\hline & 7 & 20 & 18 & 38 & 47.37 & $0 / 20$ & 0 \\
\hline & 8 & 23 & 24 & 47 & 51.06 & $0 / 23$ & 0 \\
\hline & 9 & 30 & 41 & 71 & 57.75 & $0 / 30$ & 0 \\
\hline & 10 & 5 & 8 & 13 & 61.54 & $0 / 5$ & 0 \\
\hline & 11 & 16 & 0 & 16 & $0.00 * *$ & $0 / 16$ & 0 \\
\hline & 12 & 7 & 0 & 7 & $0.00 * *$ & $0 / 7$ & 0 \\
\hline & 13 & 4 & 1 & 5 & 20.00 & $0 / 4$ & 0 \\
\hline & 14 & 14 & 21 & 35 & 60.00 & $0 / 14$ & 0 \\
\hline Total & & 178 & 178 & 356 & & 0 & 0 \\
\hline
\end{tabular}




\section{Table 3(on next page)}

Mitochondrial cytochrome c oxidase subunit I (COI) and microsatellite loci analyses for parental individuals (F0) and for parthenogenetic F2 and F3 offspring obtained from the hybrid Artemia crosses.

Genotypes for three microsatellite loci (allele sizes in base pairs) are shown. Diagnostic alleles, that is, alleles present in the rare male grandfather and not in the grandmother are shown in bold in the grandfather and in the F2 and F3 offspring. ' $\varnothing$ ' indicates the presence of null alleles; 'm' indicates a rare male. COI haplotypes as named in GenBank are shown. KAZSEX03: GU591387; APD02: DQ426825; AUKOY02: KF707698; AUKOY01: KF707699. 


\begin{tabular}{|c|c|c|c|c|c|}
\hline & Sample code & Apd02 & Apd03 & Apd05 & COI \\
\hline \multirow{21}{*}{$\begin{array}{l}\text { Rare male } x \\
\text { Artemia sp. Kazakhstan }\end{array}$} & & & & & \\
\hline & F0 (F-Kaz 8) & $233-233$ & $213-245$ & $\varnothing-\varnothing$ & KAZSEX03 \\
\hline & F0 (M-Iraq 8) & $233-242$ & 208-231 & $115-\varnothing$ & APD02 \\
\hline & F2-8-2-2 & $233-233$ & 231-245 & $\varnothing-\varnothing$ & KAZSEX03 \\
\hline & F2-8-2-3 & 233-242 & 231-245 & $\varnothing-\varnothing$ & KAZSEX03 \\
\hline & F2-8-2-4 & 233-242 & 231-245 & $\varnothing-\varnothing$ & KAZSEX03 \\
\hline & F2-8-2-5 & 233-242 & 231-245 & $\varnothing-\varnothing$ & KAZSEX03 \\
\hline & F2-8-2-6 & 242-242 & 231-245 & $\varnothing-\varnothing$ & KAZSEX03 \\
\hline & F2-8-2-8 & 233-242 & 231-245 & $\varnothing-\varnothing$ & KAZSEX03 \\
\hline & F3-8-2-2-3 & $233-233$ & 231-245 & $\varnothing-\varnothing$ & KAZSEX03 \\
\hline & F3-8-2-2-5 & $233-233$ & 231-245 & $\varnothing-\varnothing$ & KAZSEX03 \\
\hline & F3-8-2-2-10 & $233-233$ & 231-245 & $\varnothing-\varnothing$ & KAZSEX03 \\
\hline & F3-8-2-2-12m & $233-233$ & 231-245 & $\varnothing-\varnothing$ & KAZSEX03 \\
\hline & F3-8-2-6-3 & 242-242 & 231-245 & $\varnothing-\varnothing$ & KAZSEX03 \\
\hline & F3-8-2-6-4 & $242-242$ & 231-245 & $\varnothing-\varnothing$ & KAZSEX03 \\
\hline & F3-8-2-6-5 & 242-242 & 231-245 & $\varnothing-\varnothing$ & KAZSEX03 \\
\hline & F3-8-2-6-7m & 242-242 & 231-245 & $\varnothing-\varnothing$ & KAZSEX03 \\
\hline & F3-8-2-8-1 & 233-242 & 231-245 & $\varnothing-\varnothing$ & KAZSEX03 \\
\hline & F3-8-2-8-2 & $233-242$ & 231-245 & $\varnothing-\varnothing$ & KAZSEX03 \\
\hline & F3-8-2-8-3 & $233-242$ & 231-245 & $\varnothing-\varnothing$ & KAZSEX03 \\
\hline & F3-8-2-8-4 & $233-242$ & 231-245 & $\varnothing-\varnothing$ & KAZSEX03 \\
\hline \multirow[t]{8}{*}{ Rare male $x$ A. urmiana } & F0 (F-Koy 15) & $233-281$ & 207-Ø & $170-\varnothing$ & AUKOY02 \\
\hline & Fo (M-Iraq 15) & 254-233 & 216-231 & $115-185$ & APD02 \\
\hline & F2-15-8-A & 254-254 & $207-216$ & 185 & AUKOY02 \\
\hline & F3-15-8-A-1 & 254-254 & 216 & 185 & AUKOY02 \\
\hline & F3-15-8-A-4 & 254-254 & $207-216$ & 185 & AUKOY02 \\
\hline & F3-15-8-A-5 & 254-254 & $207-216$ & 185 & AUKOY02 \\
\hline & F3-15-8-A-6 & 254-254 & 207-216 & 185 & AUKOY02 \\
\hline & F3-15-8-A-7m & 254-254 & 207 & 185 & AUKOY02 \\
\hline \multirow[t]{8}{*}{ Rare male $x$ A. urmiana } & F0 (F-Koy 16) & $248-\varnothing$ & $208-\varnothing$ & $90-90$ & AUKOY01 \\
\hline & F0 (M-Iraq 16) & 233-251 & $216-230$ & 117-189 & APD02 \\
\hline & F2-16-7-4 & 248-251 & $\varnothing-\varnothing$ & $90-117$ & AUKOY01 \\
\hline & F3-16-7-4-1 & 248-251 & $\varnothing-\varnothing$ & $90-117$ & AUKOY01 \\
\hline & F3-16-7-4-2 & 248-251 & $\varnothing-\varnothing$ & $90-90$ & AUKOY01 \\
\hline & F3-16-7-4-3 & 248-251 & $\varnothing-\varnothing$ & 90-117 & AUKOY01 \\
\hline & F3-16-7-4-5 & 248-251 & $\varnothing-\varnothing$ & 90-117 & AUKOY01 \\
\hline & F3-16-7-4-7m & $248-251$ & $\varnothing-\varnothing$ & $90-117$ & AUKOY01 \\
\hline
\end{tabular}

